\title{
Effect of aging on the cerebral processing of thermal pain in the human brain
}

\author{
Ming-Tsung Tseng a,b,c, Ming-Chang Chiang d,*, Kong Yazhuo ${ }^{c}$, Chi-Chao Chao ${ }^{\text {a }}$, Wen-Yih I. Tseng e,f \\ Sung-Tsang Hsieh ${ }^{\text {a,g,h,* }}$ \\ ${ }^{a}$ Department of Neurology, National Taiwan University Hospital, Taipei, Taiwan \\ ${ }^{\mathrm{b}}$ Section of Neurology, Department of Medicine, Far-Eastern Memorial Hospital, Taipei, Taiwan

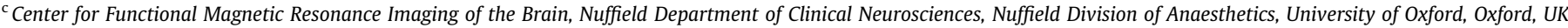 \\ ${ }^{\mathrm{d}}$ Department of Biomedical Engineering, National Yang-Ming University, Taipei, Taiwan \\ e Department of Medical Imaging, National Taiwan University Hospital, Taipei, Taiwan \\ ${ }^{\mathrm{f}}$ Center for Optoelectronic Biomedicine, National Taiwan University College of Medicine, Taipei, Taiwan \\ ${ }^{\mathrm{g}}$ Department of Anatomy and Cell Biology, National Taiwan University College of Medicine, Taipei, Taiwan \\ ${ }^{\mathrm{h}}$ Graduate Institute of Brain and Mind Sciences, National Taiwan University College of Medicine, Taipei, Taiwan
}

Sponsorships or competing interests that may be relevant to content are disclosed at the end of this article.

\section{A R T I C L E I N F O}

\section{Article history:}

Received 26 March 2013

Received in revised form 19 June 2013

Accepted 24 June 2013

\section{Keywords:}

Aging

Contact heat-evoked potential

Functional magnetic resonance imaging

(fMRI)

Voxel-based morphometry

Pain

Noxious heat

\begin{abstract}
A B S T R A C T
The perception of pain changes as people age. However, how aging affects the quality of pain and whether specific pain-processing brain regions mediate this effect is unclear. We hypothesized that specific structures in the cerebral nociceptive system mediate the effect of aging on the variation in different pain psychophysical measures. We examined the relationships between painful heat stimulation to the foot and both functional magnetic resonance imaging signals and gray matter volume in 23 healthy subjects (aged $25 \sim 71$ years). Increased age was related to decreased subjective ratings of overall pain intensity and the "sharp" quality of pain. Group activation maps of multiple linear regression analyses revealed that age predicted responses in the middle insular cortex (IC) and primary somatosensory cortex (S1) to pain stimuli after controlling for their gray matter volumes. Blood oxygenation level-dependent signals in the contralateral middle IC and S1 were related to ratings of "sharpness," but not any affective descriptors of pain. Importantly, activity in the contralateral middle IC specifically mediated the effect of age on overall pain perception, whereas activity in the contralateral S1 mediated the relationship between age and sharp sensation to pain. The analyses of gray matter volume revealed that key nociceptive cerebral regions did not undergo significant age-related gray matter loss. However, the volume of the cingulate cortex covaried with pain perception after adjusting for corresponding neural activity to pain. These results suggest that age-related functional alterations in pain-processing regions are responsible for changes in pain perception during normal aging.
\end{abstract}

(c) 2013 International Association for the Study of Pain. Published by Elsevier B.V. All rights reserved.

\section{Introduction}

Pain perception changes during normal aging [25], but its neural substrate remains unclear. The aging process is accompanied by structural and functional changes in peripheral nociceptors $[9,58,81]$, but the functional and structural alterations that occur

\footnotetext{
* Corresponding authors. Addresses: Department of Biomedical Engineering, National Yang-Ming University, Taipei, Taiwan. Tel.: +886 28267110; fax: +886 2 28210847 (M.-C. Chiang), Department of Neurology, National Taiwan University Hospital, 7 Chung-Shan South Road, Taipei 10002, Taiwan. Tel.: +886 2 23123456x8182; fax: +886223915292 (S.-T. Hsieh).

E-mail addresses: mcchiang@ym.edu.tw (M.-C. Chiang), shsieh@ntu.edu.tw (S.-T. Hsieh).
}

in pain-processing brain regions remains elusive. In humans, electrophysiological studies have shown that brain responses to pain decline with advancing age $[11,28,77]$, suggesting alterations in the central processing of pain in normal aging. Given that brain hemodynamic responses of other sensations, including vision [38], audition [39], and olfaction [85] decrease during aging, we hypothesize that a similar decline in pain processing also occurs.

The experience of pain is multidimensional and contains diverse qualities [52]. Functional changes in different pain-related brain regions have been associated with different aspects of pain [76]. For example, the somatosensory cortices and insula have been associated with the sensory quality of pain $[36,60]$, and the cingulate cortex with the affective aspects [68]. However, these cerebral structures receive similar projections from peripheral 
nerve fibers. Given that there are age-related alterations in peripheral nociceptors, it would be important to explore how the experienced quality of pain is affected by age. Surprisingly, only a limited number of behavioral studies have investigated this issue [34], and it is not yet known whether aging is accompanied by changes in the cerebral activity that is related to specific qualities of pain. The present study examined whether the influence of age on distinct pain psychophysics is mediated by specific structures in the central nociceptive system.

In addition to functional changes, aging-related structural changes in cerebral areas that are related to pain processing are not well characterized. Normal aging is accompanied with a gradual loss of brain tissue [44,53,69], including cortical areas related to pain, such as the insula [29], cingulate [74], and somatosensory cortices [69]. Despite accumulated studies describing the relationship between chronic pain and volumetric changes in pain-associated regions $[2,26,44,53]$, limited research has investigated gray matter correlates of acute physiological pain [20,31]. Whether the morphologic changes of pain-associated regions independently contribute to the altered experience of pain in normal aging is unknown. In addition, structural changes potentially confound the evaluation of neural responses to pain [66]. Thus, adjustment of the measured blood oxygen level-dependent (BOLD) responses for the regional volume will help to depict the full picture of agerelated functional alterations to pain. Similarly, the relationship between structural changes and pain may be better elucidated by correcting for age-related signal changes in the same region.

Most imaging studies of pain in the healthy population involve participants with a narrow range of age, making the impact of age impossible to fully explore. We recruited a group of healthy participants with a large age range to elucidate age-related functional and structural changes in pain-processing brain regions. We hypothesized that aging would accompany a change in the psychophysical measure of the distinct quality of pain, which would be mediated by neural activity in the cerebral nociceptive system.

\section{Materials and methods}

\subsection{Subjects}

Twenty-three healthy right-handed normal subjects ( 9 men and 14 women) between 25 and 71 years of age (mean 45.6 years) participated in the study. Nine females were premenopausal, and they were scanned during days $5 \sim 10$ of their menstrual cycle. Each subject's personal history was taken using questionnaires to review neurologic systems in order to exclude latent neurologic disorders. Neurological examinations were performed to exclude any neuropsychiatric disorder or pain symptoms. Because clinically silent cerebrovascular pathology in persons of advanced age may affect neurovascular coupling and BOLD signals [18], subjects with the presence of cerebral infarcts, hemorrhage, or subcortical arteriosclerotic encephalopathy on T2 magnetic resonance imaging (MRI) were not enrolled in the current study. The study protocol was approved by the Ethics Committee of National Taiwan University Hospital, Taipei, Taiwan, and informed consent was obtained from all subjects before the experimental procedures.

\subsection{Thermal stimulation}

Thermal stimulation was delivered by a contact heat-evoked potential stimulator (PATHWAY sensory evaluation system; Medoc, Ramat Yishai, Israel) via a 27-mm-diameter circular thermofoil $\left(572 \mathrm{~mm}^{2}\right)[11,78]$. The thermofoil permitted a very rapid heating rate (up to $70^{\circ} \mathrm{C} / \mathrm{s}$ ) and a fast cooling rate (up to $40^{\circ} \mathrm{C} / \mathrm{s}$ ). The stimulus temperature in this study was defined as the temper- ature of thermofoil applied to the skin. Cooling began immediately after the thermode reached its target stimulus temperature.

\subsection{Image acquisition}

The functional MRI (fMRI) study was performed using a 3T MRI scanner (Trio; Siemens, Erlangen, Germany). The subject's head was comfortably positioned inside a receive-only 8-channel head coil, padded with sponges, and fixed with a strap across the forehead to minimize head motion. Each subject was provided with earplugs to minimize scanner noise. A whole-brain high-resolution T1-weighted image was acquired using 3D acquisition with magnetization-prepared rapid gradient echo sequence (repetition time $[\mathrm{TR}]=1380 \mathrm{~ms}$; echo time $[\mathrm{TE}]=2.6 \mathrm{~ms}$; time to inversion $[\mathrm{TI}]=800 \mathrm{~ms}$; flip angle $=15^{\circ}$; field of view $[\mathrm{FOV}]=25 \times 25 \mathrm{~cm}$; slice thickness $=1 \mathrm{~mm} ; 192$ slices in axial plane; acquisition matrix $=256 \times 256$; acquired resolution $=0.98 \times 0.98 \times 1.00 \mathrm{~mm}$ ). Gradient-echo echo planar imaging was used to acquire BOLD contrast data. The acquisition parameters were TR/TE of $3000 / 30 \mathrm{~ms}$, a flip angle of $90^{\circ}$, a $64 \times 64$ matrix, a FOV of $250 \times 250 \mathrm{~mm}$, and a slice thickness of $3.9 \mathrm{~mm}$, resulting in a voxel size of $3.9 \times 3.9 \times 3.9 \mathrm{~mm}$. In total, 35 horizontal slices along the anterior/posterior commissure line were obtained covering the entire brain. The first 4 images were discarded to account for spin saturation effects.

\subsection{Experimental protocol}

We used a block-designed fMRI protocol similar to our previous designs [78]. One hour before fMRI scanning, subjects were brought to a waiting room where they were familiarized with the instructions for the experiment and the rating procedure. The imaging session consisted of one T2-weighted image, one T1weighted anatomical scan, and one functional scanning run. The thermode was strapped to the dorsum of the right foot without causing any pressure, and the stimulation site was fixed during the functional scan. The stimulus sequence during the functional scanning run consisted of 5 presentations of the same stimulus that ramped from the baseline $32^{\circ} \mathrm{C}$ ( 36 seconds) to $44^{\circ} \mathrm{C}$ (12 seconds) at $20^{\circ} \mathrm{C} / \mathrm{s}$ and then returned to the baseline temperature at $40^{\circ} \mathrm{C} / \mathrm{s}$. Immediately before scanning, subjects were instructed to refrain as much as possible from moving throughout the imaging session, to pay attention to the stimuli, and to keep in mind the sensation they felt and report it after each functional scan was completed. Subjects were also instructed to keep their eyes closed during stimulation. After the fMRI scan, subjects were asked to verbally rate the average perception for the 5 stimuli. In order to obtain an overall, rather than unidimensional, measure of pain perception and to minimize errors in the elderly subjects [41], we used a verbal rating scale (VRS) ranging from 0 to 10 : with 0 indicating no sensation, 4 just painful, and 10 unbearable pain, which had been adopted in previous studies $[45,57,71]$. Since one of the aims of this study was to examine age-related changes in pain quality, the Short-Form McGill Pain Questionnaire [51], which has been used to characterize changes in different qualities of pain perception in healthy subjects [42,49], was employed to assess 11 sensory and 4 affective descriptors [71]. Each descriptor was rated on a 4 -point scale from no (0) to severe (3) sensation (Table 1 ).

\subsection{Functional image analysis}

fMRI image processing and data analysis were performed using SPM8 (www.fil.ion.ucl.ac.uk/spm) [22] implemented in MATLAB (MathWorks, Sherborn, MA, USA). Briefly, the fMRI data series was realigned to the first volume in each scan sequence and resliced with sinc interpolation to correct for motion artifacts [23]. 
Table 1

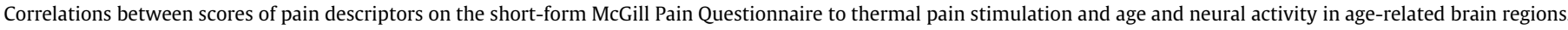

\begin{tabular}{|c|c|c|c|c|}
\hline & \multicolumn{4}{|c|}{ Correlation ( $r$, raw $P$-value $)$} \\
\hline & Age & Left S1 & Left mIC & Right mIC \\
\hline \multicolumn{5}{|l|}{ Sensory descriptor } \\
\hline Throbbing & $-0.317,0.140$ & $0.556,0.006^{\mathrm{a}}$ & $0.280,0.196$ & $-0.283,0.191$ \\
\hline Shooting & $-0.281,0.193$ & $0.173,0.431$ & $0.385,0.07$ & $0.007,0.976$ \\
\hline Stabbing & $-0.400,0.058$ & $0.41,0.052$ & $0.526,0.01^{\mathrm{a}}$ & $0.350,0.102$ \\
\hline Sharp & $-0.578,0.004^{\mathrm{a}, \mathrm{b}}$ & $0.71,0.0001^{\mathrm{a}, \mathrm{b}}$ & $0.724,<0.0001^{\mathrm{a}, \mathrm{b}}$ & $0.566,0.005^{a}$ \\
\hline Cramping & $-0.160,0.466$ & $0.389,0.067$ & $0.158,0.471$ & $0.221,0.311$ \\
\hline Gnawing & $0.018,0.934$ & $0.413,0.050$ & $0.174,0.428$ & $0.164,0.454$ \\
\hline Hot-burning & $0.051,0.816$ & $0.208,0.340$ & $0.147,0.503$ & $0.159,0.469$ \\
\hline Aching & $-0.360,0.092$ & $0.265,0.221$ & $0.143,0.514$ & $0.228,0.296$ \\
\hline Heavy & $-0.315,0.143$ & $0.19,0.384$ & $0.219,0.316$ & $0.066,0.765$ \\
\hline Tender & $-0.241,0.269$ & $0.438,0.037$ & $0.258,0.235$ & $0.469,0.024$ \\
\hline Splitting & $-0.331,0.123$ & $0.265,0.222$ & $0.399,0.060$ & $0.215,0.324$ \\
\hline \multicolumn{5}{|l|}{ Affective descriptor } \\
\hline Tire-exhausting & $-0.286,0.185$ & $0.313,0.146$ & $0.109,0.621$ & $0.247,0.256$ \\
\hline Sickening & $-0.036,0.872$ & $0.234,0.282$ & $0.141,0.520$ & $0.048,0.827$ \\
\hline Fearful & $-0.028,0.898$ & $0.068,0.757$ & $0.214,0.326$ & $-0.041,0.852$ \\
\hline Punishing-cruel & $-0.175,0.424$ & $0.188,0.389$ & $0.366,0.086$ & $0.135,0.539$ \\
\hline Total scores for sensory descriptors & $-0.514,0.012^{\mathrm{a}}$ & $0.662,0.0006^{\mathrm{a}}$ & $0.607,0.0021^{\mathrm{a}}$ & $0.426,0.043^{\mathrm{a}}$ \\
\hline Total scores for affective descriptors & $-0.128,0.560$ & $0.241,0.268$ & $0.310,0.1502$ & $0.084,0.705$ \\
\hline
\end{tabular}

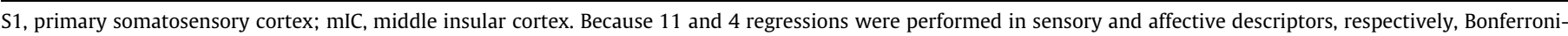

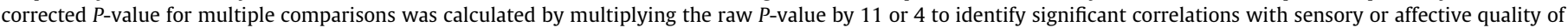
pain.

a Raw $P$-value $<0.05$ (Pearson's correlation).

b Bonferroni-corrected $P$-value $<0.05$.

Subjects enrolled in the present study had no scans with sudden head movements $>2 \mathrm{~mm}$. The resulting mean image was registered to the corresponding T1-weighted anatomical image. To enable intersubject analysis, the T1-weighted image of each subject was normalized to the standard Montreal Neurological Institute (MNI) template [16], and the normalization parameters were then applied to the functional data of that subject. The resampled voxel volume of the normalized images was $2 \times 2 \times 2 \mathrm{~mm}$. Subsequently, data were smoothed using an isotropic Gaussian kernel with an 8-mm full width at half maximum (FWHM). Conditionspecific effects were estimated using the general linear model in SPM8, which was constructed by convolving a boxcar sequence with the hemodynamic response function [22]. A high-pass filter with a cutoff period of 128 seconds was used to remove low-frequency noise. Statistical parametric maps of brain activation for the entire 12-second stimuli at the target temperatures were presented as $t$-contrasts for the 12 -second stimulation regressor vs the baseline regressor. To minimize potential confounding effects of pain-related activation, only the final 12 seconds of the $32^{\circ} \mathrm{C}$ stimulus temperature was defined as the baseline [78] because the duration of poststimulus cerebral activation to heat pain was approximately 10 seconds [12,54], and it took several additional seconds for the skin temperature to return to the baseline after a tonic stimulus delivered by the contact heat-evoked potential stimulator [30]. First-level $t$-contrasts were then entered into a second-level random-effects analysis [37].

To investigate aging effects on the central nociceptive system, we focused our analyses on major heat pain-processing brain regions in the current study, including the primary somatosensory cortex (S1), secondary somatosensory cortex (S2), insular cortex (IC), and the cingulate cortex [19]. The rationale of analysis in the current study consisted of 5 components. First, we confirmed BOLD responses in pain-related brain regions to $44^{\circ} \mathrm{C}$ stimuli. To minimize false positives [48], this mean group activation map was corrected for multiple comparisons by thresholding at $P<0.05$ family-wise error (FWE) and at a minimum cluster size of 10 contiguous voxels. Second, we employed a multiple linear regression analysis in SPM to examine whether age rather than pain intensity ratings predicted responses in cerebral regions engaged in the processing of pain. This multiple regression model corrected for FWE revealed no suprathreshold activations. Given FWE is conservative and prone to false negatives $[46,48]$ and we treated whole-brain multiple linear regression analysis as secondary exploratory analysis in the present study, we performed cluster-based multiple comparisons correction with Monte Carlo simulations to reveal spatially extended activation clusters [56]. Clusters with at least $872 \mathrm{~mm}^{3}$ and a voxel-wise threshold of $P=0.005$ were regarded as significant, which achieved an $\alpha$ value of 0.05 corrected for multiple comparisons. These thresholds were determined using Monte Carlo simulations ( $n=10,000)$ [21] implemented in the 3dClustSim program of the Analysis of Functional Neuroimages software package (http://afni.nimh.nih.gov/afni/), where the correction for multiple comparisons was restricted within a gray matter mask $\left(1,522,200 \mathrm{~mm}^{3}\right)$ that was obtained from the analysis of average group activation maps to $44^{\circ} \mathrm{C}$ stimuli and was found to be a similar size to a previous study [86]. Since participants responded to a fixed stimulus temperature, activity correlated with pain intensity ratings in the current study indeed reflected between-subject differences in pain-sensitivity. For the third component of our analysis, another whole-brain multiple linear regression analysis was used to examine regional volume of gray matter in the pain-related regions that were associated with age and pain intensity. In the fourth part of the analysis, partial regression plots were used to explore if the effects of age on pain-related functional and structural alterations persisted after correcting for corresponding structural and functional changes, respectively. Finally, mediation analyses were used to establish the causal link between age and the decrease in pain ratings across the adult lifespan.

In addition to whole brain analyses, small-volume correction [87] with FWE correction for multiple comparisons at a level of $P<0.05$ was also performed within the S1 and S2 as regions of interest. Both regions were selected because they are implicated in the processing of sensory aspect of pain [76], and our behavioral data showed the specific influence of age on sensory rather than affective descriptors of pain (see Results). Since there was no reliable anatomical mask that characterized the somatotopic correspondence of the foot areas in the brain, we selected regions of interest (ROIs) for S1 and S2 from the activated areas with respect to thermal pain stimuli to the foot dorsum in previous fMRI studies 
[54]. ROIs for S1 and S2 were then defined as the intersection of these activated areas and the S1 and S2 regions labeled in the automated anatomical labeling atlas (Supplementary Fig. 1). Mean BOLD signals across all voxels within S1 and S2 were extracted for the subsequent simple regression, partial correlation, and mediation analyses (Supplementary Fig. 2). In the current study, the midcingulate cortex (MCC) was defined as the supracallosal part of the cingulate cortex, whereas the anterior cingulate cortex (ACC) was designated as the subdivision anterior to the MCC according to previous anatomical and functional studies [72,82].

\subsection{Mediation analysis}

Given that responses in the contralateral middle IC and S1 were correlated with age and specifically predicted pain psychophysics (see Results), we hypothesized a causal model where the influences of age (the independent variable) on pain intensity ratings (the outcome variable) were mediated by an intermediate variable, or the mediator [73]. In other words, we assumed that the functional activity in pain-processing cerebral areas mediates the causal effect of aging on pain perception. We tested this causal model using the mediation analysis method [7] (see Fig. 4A for detailed explanation), where the statistical significance of the mediator (the mean BOLD signals within the contralateral middle IC and S1) was determined by the proportion of covariance between age and pain intensity ratings that was accounted for by the full model containing 3 variables (age $\rightarrow$ BOLD signals in the pain-processing brain regions $\rightarrow$ pain psychophysics) compared to the null, or the unmediated model (ie, age $\rightarrow$ pain psychophysics) [84]. Because a small sample size may bias the evaluation of the mediating effect [63], a nonparametric bootstrapping procedure was employed to confirm the effect, which serves to enhance the confidence of statistical results in a small sample [64]. This analysis was first performed using the mediation toolbox implemented on MATLAB developed by T.D. Wager (http://wagerlab.colorado.edu/files/ tools/mediation.html). The significance of the indirect effects was further confirmed in an SPSS macro command set "PROCESS" developed by Hayes [35], which drew 10,000 bootstrapped samples to estimate a bias-corrected $95 \%$ confidence interval (CI). A $\mathrm{CI}$ that does not overlap zero indicates significant mediating effects.

\subsection{Voxel-based morphometry}

Structural images were analyzed using VBM8 toolbox implemented in SPM8 (http://dbm.neuro.uni-jena.de/vbm/). Using high-dimensional DARTEL (Diffeomorphic Anatomical Registration
Through Exponentiated Lie Algebra) normalization algorithms [3], individual T1-weighted images were normalized to the DARTEL template in MNI space, re-sliced to $1.5 \mathrm{~mm} \times 1.5 \mathrm{~mm} \times 1.5 \mathrm{~mm}$, and segmented into gray matter, white matter, and cerebrospinal fluid [4]. To investigate local volumetric changes corrected for individual brain size, Jacobian modulation for nonlinear warping was performed to adjust for global differences in the brain volume. After preprocessing, we visually examined all normalized bias-corrected volumes and the homogeneity of gray matter images to ensure that segmentation and normalization had not yielded any artifacts. The resulting images were then smoothed with an isotropic Gaussian kernel of 8-mm FWHM, and were then entered into the voxel-based statistical analysis based on the general linear model in SPM8. To identify areas showing age-related loss in gray matter and to investigate if pain perception changed as a function of morphologic alterations in brain regions responsible for processing pain, we performed a whole-brain voxel-based multiple linear regression using age, gender [50], and the VRS rating as covariates. Using the same Monte Carlo simulation principle described above, the results of voxel-based morphometry were thresholded at a single-voxel significance level of $P<0.005$ and minimum cluster size of $607 \mathrm{~mm}^{3}$, which corresponded to a family-wise error rate of $\alpha<0.05$. Activations surviving FWE-corrected $P<0.05$ were also marked. For both fMRI and voxel-based morphometry data, the BOLD signal changes and regional meanadjusted gray matter volumes within ROIs were extracted by SPM MarsBaR toolbox [79].

\subsection{Statistics}

Simple regression analysis was performed to analyze linear correlation using Pearson's correlation coefficient test. Partial regression analyses controlling for gender, VRS ratings, and corresponding BOLD signals or gray matter volumes were employed to disentangle the relationship between age and structural or functional changes. A $P$ value of $<0.05$ was considered statistically significant. The statistical analysis was performed using SPSS (Chicago, IL) and GraphPad Prism (GraphPad Software, San Diego, CA).

\section{Results}

\subsection{Correlation of the age with perceived pain intensity}

The overall pain sensation for $44^{\circ} \mathrm{C}$ stimulus temperature, as indicated by VRS ratings, was negatively correlated with age (Fig. 1A). For the diverse sensory qualities of pain, the degree of
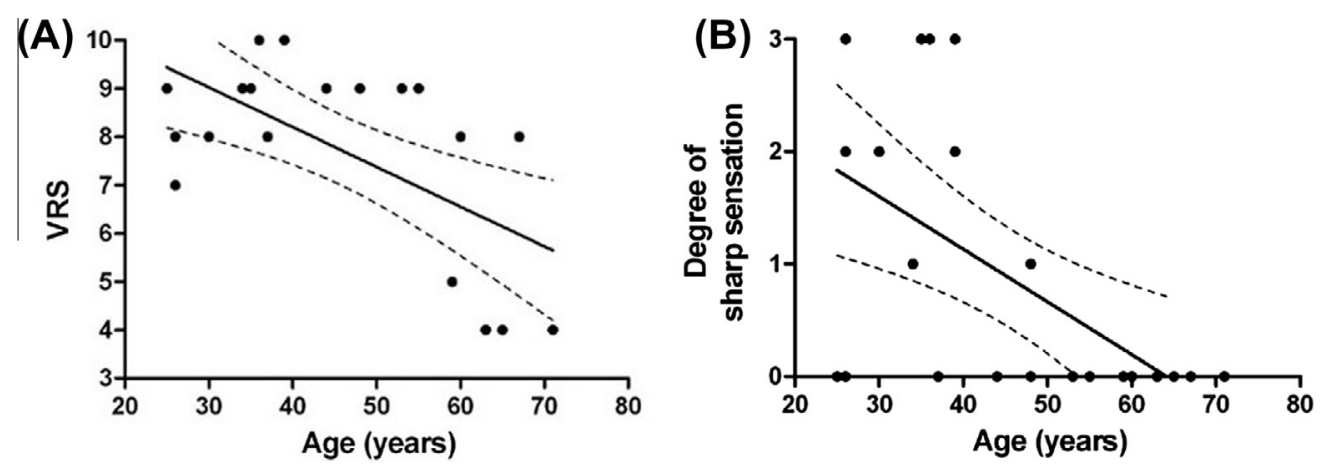

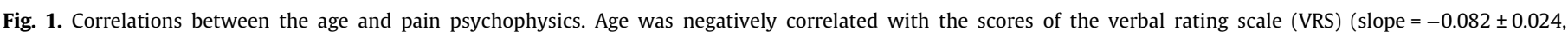

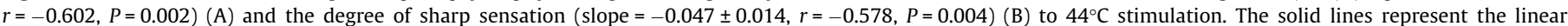

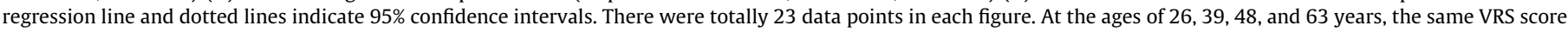
$(8,10,9$, and 4 , respectively) was reported by 2 participants. Two subjects aged 63 years rated the degree of sharp sensation as 0 . 
sharp sensation (Fig. 1B, Table 1) showed a significant inverse correlation with age. In contrast, scores of all affective descriptors were independent of age.

\subsection{Pain-related brain activations associated with age vs pain perception}

In our subjects, painful heat stimulation elicited activations in typical pain-related cerebral regions [61], including S1, S2, IC, ACC, prefrontal cortex, and thalamus (Supplementary Fig. 3, Supplementary Table). To examine whether age predicted responses in pain-related brain regions, we performed a whole-brain multiple linear regression analysis with age, gender, and VRS ratings as covariates. Cerebral activity predicted by VRS ratings included the contralateral IC, S2, and supplementary motor area (Fig. 2, Table 2). By contrast, an increase in age was specifically associated with a decrease in BOLD signals in the bilateral ICs, contralateral S1, and premotor cortex (Fig. 2, Table 2). Responses within the contralateral IC and S1 paralleled the degree of "sharp" quality of pain but not any affective descriptor (Table 1 ). These findings not only showed that age and pain intensity ratings predicted responses to heat pain stimuli in both distinct and shared cortical regions implicated in pain processing, but also suggested that the effect of age on pain quality was associated with specific pain-processing structures.

\subsection{Gray matter volume changes in pain-related brain regions during aging}

We then examined the impact of age on the volumetric changes in the gray matter of pain-processing brain regions. Results of a whole-brain multiple linear regression analysis using age, gender, and VRS ratings as covariates showed that age-associated loss of volumes mainly developed in the prefrontal cortex and temporal lobe over the entire brain (Fig. 3, Table 3). None of the main pain-related regions showed age-related gray matter loss. In contrast, among these regions, volumes in the MCC and ACC were predicted by VRS ratings (Fig. 3, Table 3). The association between VRS ratings and the volumes in the ACC (partial regression analysis, $r=0.675, P=0.001$ ) and MCC (partial regression analysis, $r=0.736, P<0.001$ ) remained significant after accounting for the effects of age, gender, and regional BOLD signals to pain.

We then investigated whether the effects of age on brain activations to pain (Fig. 2, Table 1) persisted after correcting for corresponding volumetric changes. Intriguingly, the association between age and BOLD signals in the contralateral middle IC (partial regression analysis, $r=-0.637, P=0.003$ ), ipsilateral middle IC $(r=-0.693, P=0.001)$ and contralateral S1 $(r=-0.649, P=0.002)$ remained significant after accounting for the effects of gender, VRS ratings, and regional gray matter volume. Thus, these analyses suggested that age specifically affected BOLD signal changes to pain on the middle IC and S1.

\subsection{Effects of age on pain psychophysics mediated by brain activity}

We further examined whether age by itself had its direct influences on pain perception across the adult lifespan. Since pain ratings (Fig. 1) varied with age, we performed another multiple linear regression analysis to clarify the factors determining pain psychophysics. The score of the VRS or degree of sharp sensation was entered as the dependent variable, and age, gender, and BOLD signals in age-related regions (bilateral middle ICs and contralateral S1, Fig. 2) were entered as the independent variables. Only the BOLD signal in the contralateral middle IC (standardized $\beta=0.745$, $t=5.11, P<0.001$ ) predicted ratings of the VRS. Age (standardized $\beta=-0.573, t=-2.389, P=0.028$ ) as well as responses in the
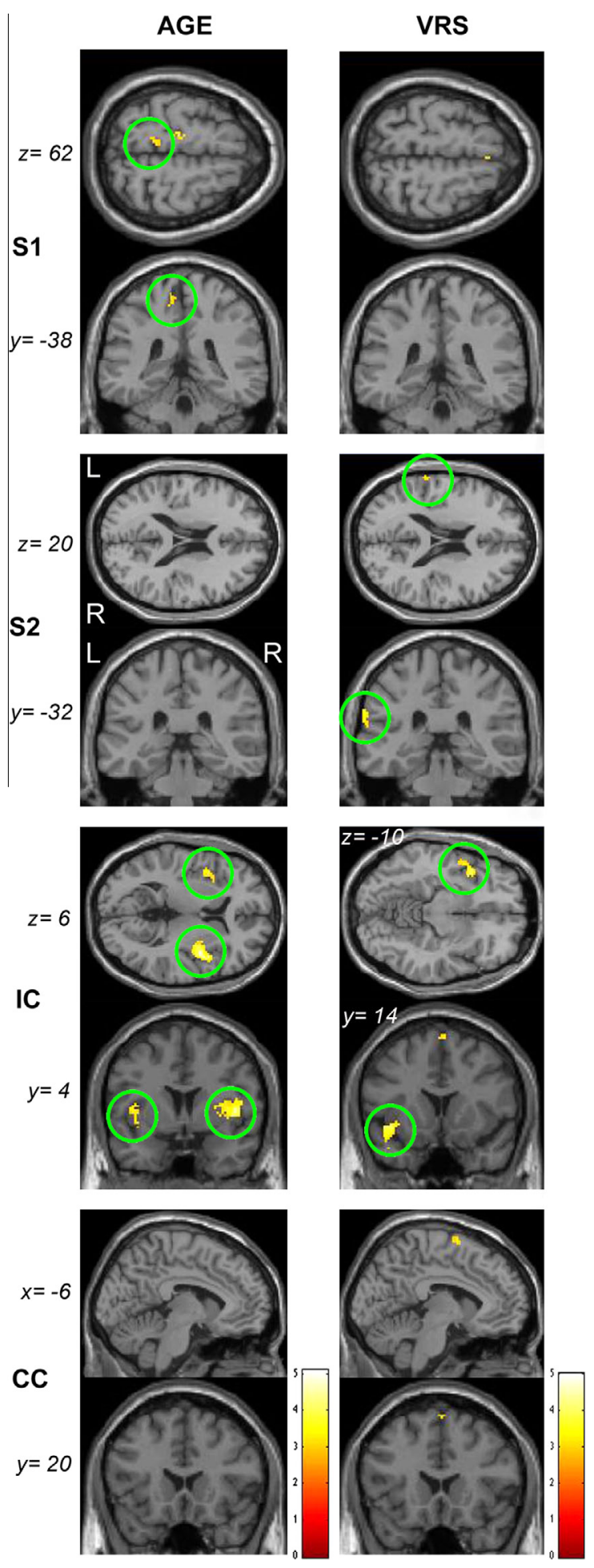

Fig. 2. Group maps of multiple linear regression analyses for functional magnetic resonance imaging data in the pain-processing brain regions. Regional blood oxygen level-dependent signals to thermal pain stimuli that were negatively correlated with age and positively correlated with ratings of verbal rating scale (VRS) were overlaid on the canonical T1-weighted brain image. The bars on the right side of group maps show the range of $t$-scores for SPM8. CC, cingulate cortex; IC, insular cortex; L, left; R, right; S1, primary somatosensory cortex; S2, secondary somatosensory cortex.

contralateral middle IC (standardized $\beta=0.761, t=3.449$, $P=0.003$ ) and $\mathrm{S} 1$ (standardized $\beta=0.630, t=2.891, P=0.010$ ) were all significant predictors for the degree of sharp sensation. 
Table 2

Areas activated in a multiple linear regression analysis using age, gender, and scores of verbal rating scale (VRS) as independent variables.

\begin{tabular}{|c|c|c|c|c|c|}
\hline \multirow[t]{2}{*}{ Region } & \multirow[t]{2}{*}{ Side } & \multicolumn{4}{|l|}{$t[\mathrm{x}, \mathrm{y}, \mathrm{z}(\mathrm{mm})]$} \\
\hline & & Age (negative correlation) & $P$ value & VRS (positive correlation) & $P$ value \\
\hline \multicolumn{6}{|c|}{ Pain-related area } \\
\hline $\mathrm{S} 1$ & Left & $3.14(-10,-38,62)$ & $0.003^{\mathrm{a}}$ & & \\
\hline $\mathrm{S} 2$ & Left & & & $3.41(-64,-32,22)$ & $0.001^{\mathrm{a}}$ \\
\hline \multirow[t]{2}{*}{ IC } & Left & $3.80(-40,8,6)$ & 0.001 & $4.00(-40,14,-10)$ & $<0.001$ \\
\hline & Right & $5.10(40,0,6)$ & $<0.001$ & & \\
\hline \multicolumn{6}{|c|}{ Frontal lobe } \\
\hline SMA & Left & & & $5.02(-2,4,74)$ & $<0.001$ \\
\hline
\end{tabular}

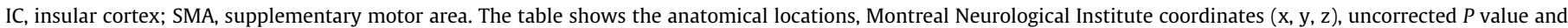
$t$-scores of peak voxels. Based on Monte Carlo simulation, only voxels surviving a threshold of $P<0.005$ uncorrected with an extent size of 872 mm ${ }^{3}$ are reported.

a Activations in the primary somatosensory cortex (S1) $\left(288 \mathrm{~mm}^{3}\right)$ and secondary somatosensory cortex (S2) $\left(600 \mathrm{~mm}{ }^{3}\right)$ were smaller than the extent threshold in the group analysis but survived $P<0.05$ using small-volume correction with familywise error correction.

Given that activities in the contralateral middle IC and S1 not only correlated with age (Fig. 2) but also predicted pain psychophysics as described above, we performed the mediation analyses in both regions to test whether the effects of age on pain psychophysics were mediated through functional changes in these areas. Specifically, we hypothesized that the IC was involved in overall pain perception given its diverse connections with broad brain regions and complex functions [17], and the S1 was linked to the sharp sensation of pain based on its association with sensory-discriminative aspect of pain [76]. We used 1) BOLD signals of the contralateral middle IC or S1 as mediator (M), 2) age as independent variable (X), and 3) VRS ratings (with IC) or the degree of sharp sensation (with $\mathrm{S} 1$ ) as outcome variable $(\mathrm{Y})$. As shown in Fig. 4, the mediation analyses confirmed our hypotheses. The direct effect (c') from age to VRS ratings (95\% CI -0.076 0.060) or sharp sensation (95\% CI -0.051 0.016) became nonsignificant after adjusting for the mediation effect, which indicated an indirect impact of age on pain perception. The middle IC was not involved in the relationship between age and sharp sensation (95\% CI $0.075 \sim 0.0007$ ), nor did the S1 mediate the association between age and VRS ratings (95\% CI $-0.042 \sim 0.035$ ). We also examined alternative models in Fig. $4 \mathrm{~B}$ and $\mathrm{C}$ by treating age as mediator, and neural activity as independent variable to enhance the confidence [70], but confidence intervals of these models crossed zero, indicating nonsignificant mediation effects.

Taken together, these findings indicate that the effects of aging on heat pain psychophysics were mediated by neural response to pain stimuli in the middle IC and S1.

\section{Discussion}

In the current study, age affected the sensory quality of heat pain as well as responses in corresponding cerebral structures (the IC and S1). This effect was independent of age-related changes in gray matter volume. Above all, this effect was mediated by neural response to pain stimuli in the middle IC and S1. These results not only extend the previously documented effects of aging on physiology of heat pain-evoked potentials $[11,28,77]$, but provide a mechanistic explanation of the influence of age on pain perception.

\subsection{Aging effects on pain perception and its brain activations}

The present study showed that age specifically affected responses to heat pain in the middle IC and S1. This finding is in contrast to a previous study that indicated that the basal ganglia were the only structures related to age-dependent changes in pressure pain [15]. Taken together, these observations suggest that the effect of age may be mediated through different brain areas in different types of pain. Our multiple regression analysis further suggested that pain-activated regions could be designated as being predicted by age (S1), pain intensity rating (S2), or both (IC). Since age and pain perception were not orthogonalized against each other (Fig. 1A), this result does not suggest independent contributions of each variable to distinct brain activity. Considering that age is supposed to influence pain perception and it is unlikely the opposite way, the proportion of variance in fMRI BOLD signals explained by age may be underestimated as some of its effect is hidden in the variance explained by pain intensity score, which would lead to false negativity in age-related effect on fMRI BOLD responses. In fact, S1 activity was correlated with pain intensity ratings in previous functional imaging studies, including ours $[8,14,78]$. When we considered age as an independent variable to brain activations, however, S1 activity was actually predicted by age. This important observation suggests that the influence of age on cerebral activity to pain was underestimated in previous functional imaging studies.

Psychophysically, age-related reduction in the activity of the middle IC and S1 was associated with the decline in the sensory quality of pain (sharpness), but was unrelated to the affective quality of pain. This result is consistent with previous findings on the differential influences of age on various pain dimensions [34]. Moreover, our psychophysical finding emphasizes the importance of assessing changes in pain characteristics during aging because most studies focus on the changes in sensitivity to pain. The affective descriptors listed in Table 1 encompassed negative emotions elicited by pain, which is closely linked to the unpleasantness of pain rather than its sensory domain [65,67]. Given that the S1 and IC have been implicated in processing sensory aspects of pain $[36,60]$, these observations suggest that aging specifically alters structures in the lateral pain pathway. However, pain information collected by peripheral nociceptors is also relayed to brain areas engaged in affective and motivational features of pain, particularly the ACC [68], which was free of the influence of age in our analysis. Our results thus provide evidence in regard to the role of the supraspinal pain-related regions in the impact of age on the experience of pain. The reason why aging processes selectively targeted the sensory aspect of pain and corresponding structures requires further elucidation.

\subsection{Structural changes in pain-related brain regions during aging}

Our voxel-based morphometry analysis revealed age-associated gray matter loss in the prefrontal cortex and temporal lobe. This pattern was consistent with previous pathology and structural imaging studies in the human brain $[1,69,74,75]$ and indicated that 

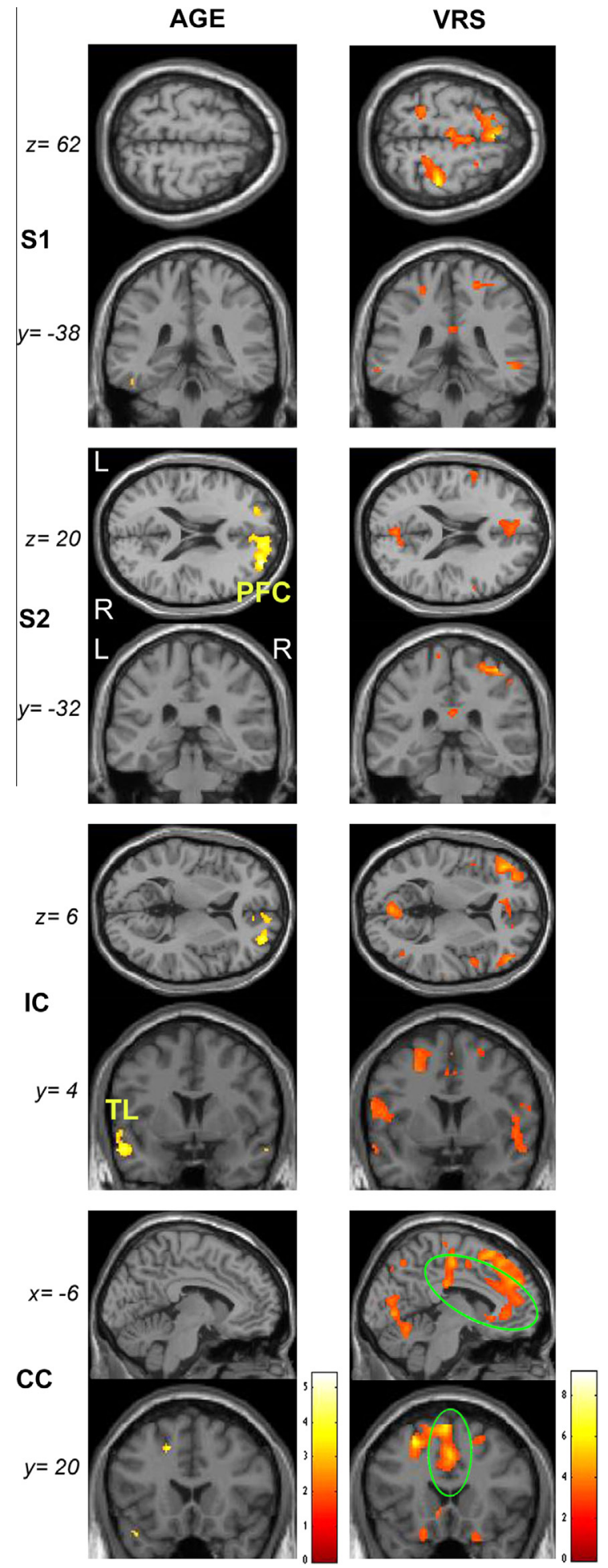

Fig. 3. Group maps of multiple linear regression analyses of gray matter volume in the pain-related brain regions. Brain regions whose gray matter volumes were negatively correlated with age and positively correlated with ratings of verbal rating scale (VRS) were overlaid on the canonical T1-weighted brain image. Prefrontal cortex (PFC) and temporal lobe (TL) showing loss of volumes were marked. The bars on the right side of group maps show the range of $t$-scores for SPM8. CC, cingulate cortex; IC, insular cortex; L, left; R, right; S1, primary somatosensory cortex; S2, secondary somatosensory cortex.

our study cohort was not a biased one. In contrast, gray matter volumes in pain-related brain regions did not covary with age, suggesting that aging-related functional changes identified above were independent of structural alterations. The preserved volumes of the key central nociceptive components might be interpreted as the vital role of pain for survival.

In pain-processing areas of the brain, the volume of the cingulate cortex was associated with pain perception. This finding is in line with previous work that detected correlations between the gray matter volume in the cingulate cortex and subjective pain sensitivity [20,31]. Specifically, the portion of the cingulate cortex correlated with pain perception in the current study resided in the anterior and posterior portions of the MCC, as well as the perigenual and subgenual parts of the ACC $[72,82]$. There are reciprocal connections between the anterior MCC and cognition-related regions in the prefrontal cortex, subcortical emotion-related regions such as the amygdala, and motor-related regions. As a result of this, the anterior MCC has been implicated in integrating negative affects and cognitive functions to adopt appropriate behaviors in response to a pain stimulus [72]. In addition, anterior MCC and perigenual ACC are associated with pain-related fear [83], emotional appraisal [62,65], and cognitive aspects such as attention [80] and expectation [59], whereas the subgenual ACC is engaged in autonomic regulation [82]. Taken together, the correlation of cingulate volume with pain perception as well as the lack of agerelated reduction in gray matter and neural activity in these cingulate subregions suggests their preserved role in executing emotional and cognitive functions to pain experiences in normal aging.

\subsection{Mediation of age effects via the middle insula and S1 on pain perception}

Our analyses revealed that fMRI signals in the middle IC and S1 mediated the statistical relationship between age and pain psychophysics. Since there was no gray matter loss in either region, these mediating effects indicate that age affected pain psychophysics via functional rather than structural changes in cerebral nociceptive centers. Such observations provide direct support for our hypothesis that, as age increases, decreased neural activity in pain-processing brain regions play a role in the reduction of pain perception.

Although the significant results of the mediation models argue for a role of the insula and S1 in the age-pain relationship, the alternative interpretations include secondary phenomena due to peripheral changes, in addition to being the cause of reduced pain perception in these areas. The periphery changes could affect the quantity of nociceptive signals that are "received" in S1. In fact, the association between age and sharp sensation (first pain) but not hot-burning sensation (second pain) in the current study is compatible with the selective effects of age on A $\delta$ fibers (subserving first pain) rather than C fibers (subserving second pain) [9,33]. Nevertheless, evidence suggested that S1 activity was particularly engaged in first pain, whereas the S2 and ACC, which were relatively independent of age according to our results, are associated with second pain [62]. Therefore, the mediating effect of the S1 on age-related decline in sharp quality of pain extends on observations of peripheral mechanisms of pain and may represent the cortical substrate for the alterations in pain qualities in normal aging. Another confounding factor is that heat sensitivity also decreases during aging [47]. Recent evidence showed that the ratings for heat sensation contribute more to the activations in somatosensory cortices than pain perception [55]. As such, the mediation effect of age on S1 activity in response to pain observed here might be confounded by heat perception. However, the fact that we did not identify correlations between the degree of heat sensation and age or neural responses in age-related regions (middle IC and S1) (Table 1) argues against a major contribution of heat sensation in our mediation analysis. Future studies combining both peripheral and central factors and innocuous heat stimuli would provide 
Table 3

Voxel-based morphometry results of a multiple linear regression analysis using age, gender, and scores of verbal rating scale (VRS) as independent variables.

\begin{tabular}{|c|c|c|c|c|c|}
\hline \multirow[t]{2}{*}{ Region } & \multirow[t]{2}{*}{ Side } & \multicolumn{4}{|l|}{$t[\mathrm{x}, \mathrm{y}, \mathrm{z}(\mathrm{mm})]$} \\
\hline & & Age (negative correlation) & $P$ value & VRS (positive correlation) & $P$ value \\
\hline \multicolumn{6}{|c|}{ Pain-related area } \\
\hline ACC & Left & & & $4.20(-10,38,1)$ & $<0.001$ \\
\hline aMCC & Right & & & $5.26(2,21,39)$ & $<0.001$ \\
\hline pMCC & Right & & & $5.00(6,-22,34)$ & $<0.001$ \\
\hline \multicolumn{6}{|l|}{ Frontal lobe } \\
\hline SFG & Left & $3.53(-22,50,22)$ & 3.53 & & \\
\hline \multirow[t]{2}{*}{ MFG } & Left & $4.65(-24,27,30)$ & $<0.001$ & $9.17(-26,15,49)^{\mathrm{a}}$ & $<0.001$ \\
\hline & Right & $5.41(32,56,13)^{\mathrm{a}}$ & $<0.001$ & $4.26(42,24,34)$ & $<0.001$ \\
\hline \multirow[t]{2}{*}{ IFG } & Left & & & $5.23(-44,38,6)^{a}$ & $<0.001$ \\
\hline & Right & & & $4.26(50,42,6)$ & $<0.001$ \\
\hline SMA & Left & & & $5.92(-2,21,60)$ & $<0.001$ \\
\hline PCG & Right & & & $6.4(38,-28,62)$ & $<0.001$ \\
\hline OFC & Left & & & $4.52(-30,48,-12)$ & $<0.001$ \\
\hline \multicolumn{6}{|c|}{ Temporal lobe } \\
\hline \multirow[t]{2}{*}{ MTG } & Left & $5.14(-54,-1,-15)$ & $<0.001$ & $4.06(-60,-15,-9)$ & $<0.001$ \\
\hline & Right & $4.56(51,-2,-29)$ & $<0.001$ & $4.19(62,-43,-6)$ & $<0.001$ \\
\hline ITG & Left & $4.49(-52,-45,-20)$ & $<0.001$ & $3.98(-52,-49,-9)$ & $<0.001$ \\
\hline FG & Right & & & $5.55(39,-49,-14)$ & $<0.001$ \\
\hline \multicolumn{6}{|l|}{ Parietal lobe } \\
\hline SPL & Left & & & $4.74(-22,-43,57)$ & $<0.001$ \\
\hline \multicolumn{6}{|l|}{ Occipital lobe } \\
\hline MOG & Right & $3.88(36,-76,24)$ & 0.001 & & \\
\hline Cerebellum & & & & $7.07(-15,-58,-23)^{\mathrm{a}}$ & $<0.001$ \\
\hline
\end{tabular}

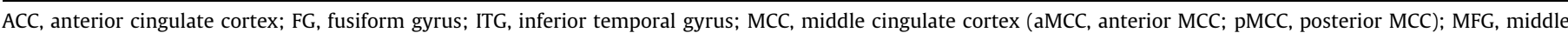

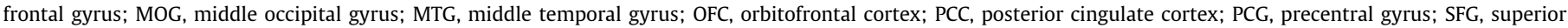
frontal gyrus; SMA, supplementary motor area; SPL, superior parietal lobule.

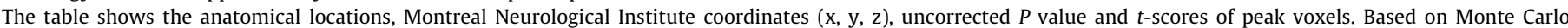
simulation, only voxels surviving a threshold of $P<0.005$ uncorrected with an extent size of $607 \mathrm{~mm}^{3}$ are reported.

a Clusters that survive family-wise error correction, $P<0.05$.
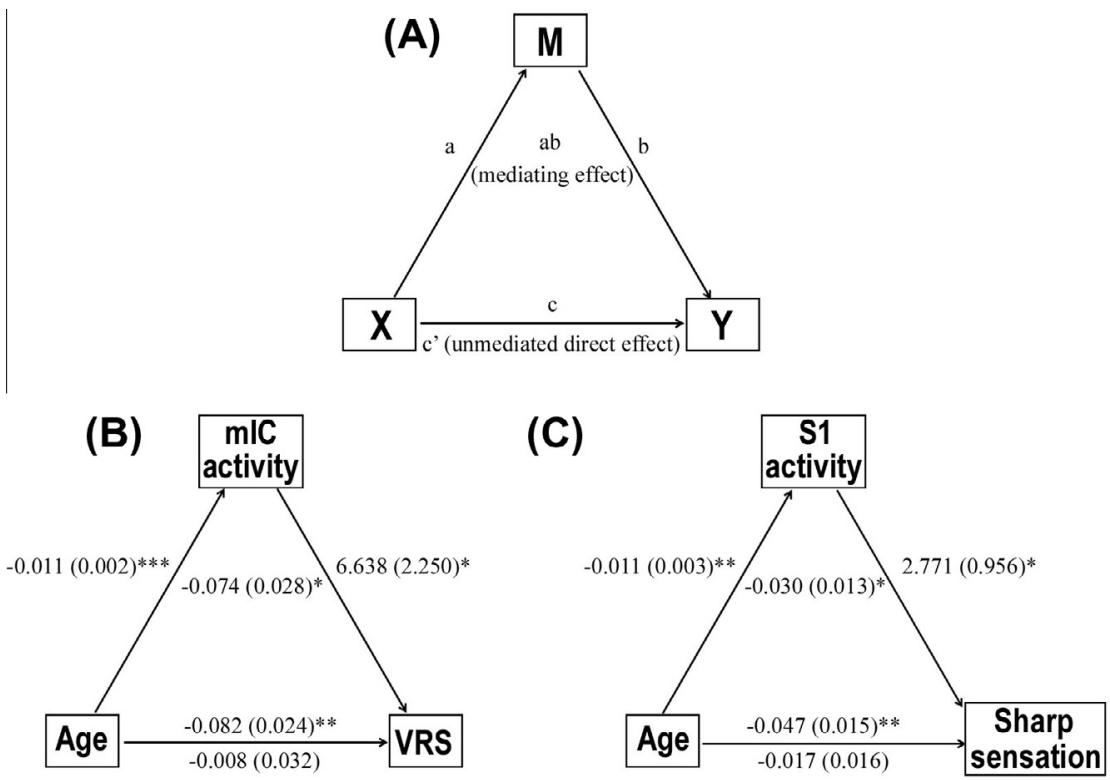

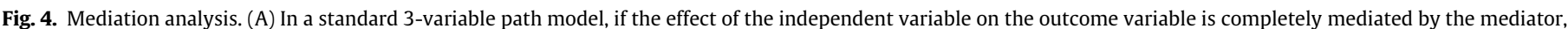

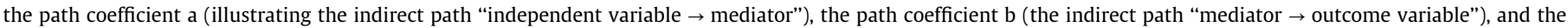

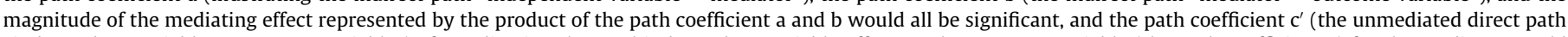

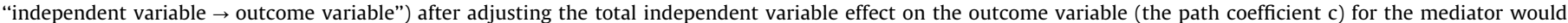

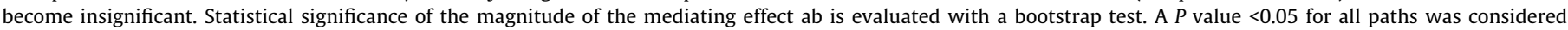

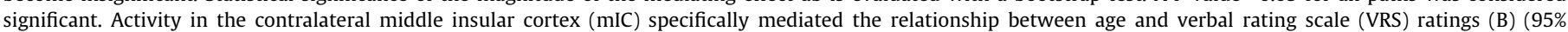

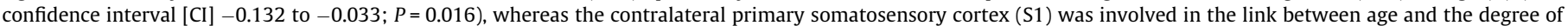
sharp sensation $(95 \% \mathrm{CI}-0.059$ to $-0.005 ; P=0.032)(\mathrm{C})$. Numbers are unstandardized coefficients, with SEM in brackets. ${ }^{*} P<0.05 ;{ }^{* *} P<0.005 ;{ }^{* * *} P<0.0005$. 
further insight into the role of the brain in the influence of age on pain perception.

The middle IC mainly receives inputs from the $\mathrm{S} 1$ and projects fibers into prefrontal cortex, supplementary motor area, S2, amygdala, and medial temporal lobe $[5,13]$. In line with this broad connectivity, this region has been related to myriad functions involving cognition, emotion, and sensorimotor processes to maintain homeostasis and guide behavioral decisions [17]. This is supported by pain studies indicating a complex role of the middle insula in the sensory dimension $[36,60]$ as well as in the cognitive domain $[6,43]$ of pain. Considering that aging is related to changes in both peripheral nerves $[9,10]$ and the spinal cord $[40]$, the mediation effect of the middle IC on the relationship between age and overall pain perception suggests that there is a convergence of age-related alterations from various anatomical levels of the pain neuraxis. The decline in nociceptive processing during advancing age may be attributed to the decay in the function of the cerebral pain-processing areas, which may not always be detected using simple nociceptive behavioral measures such as pain sensitivity or withdrawal latency to laboratory-induced pain [24,27]. The engagement of the insula provides a neural basis of age-associated deficit in brain-mediated complex behaviors upon nociceptive stimulation [32], which sheds light on a new research direction to disentangle the relationship between aging and pain in the future.

\section{Conflict of interest statement}

The authors declare no conflict of interest.

\section{Acknowledgements}

We appreciate the support from the National Health Research Institute of Taiwan, National Science Council of Taiwan, and the imaging core facility of National Taiwan University College of Medicine and National Taiwan University Hospital. Funding was received from the National Health Research Institute of Taiwan (NHRI-EX100-10045NI), National Science Council of Taiwan (NSC100-2321-B-002-007), and Translational Medicine Project of National Taiwan University College of Medicine and National Taiwan University Hospital (100C101-21).

\section{Appendix A. Supplementary data}

Supplementary data associated with this article can be found, in the online version, at http://dx.doi.org/10.1016/j.pain.2013.06.041.

\section{References}

[1] Anderton BH. Ageing of the brain. Mech Ageing Dev 2002;123:811-7.

[2] Apkarian AV, Sosa Y, Sonty S, Levy RM, Harden RN, Parrish TB, Gitelman DR Chronic back pain is associated with decreased prefrontal and thalamic gray matter density. J Neurosci 2004;24:10410-5.

[3] Ashburner J. A fast diffeomorphic image registration algorithm. Neuroimage 2007;38:95-113.

[4] Ashburner J, Friston KJ. Unified segmentation. Neuroimage 2005;26:839-51.

[5] Augustine JR. Circuitry and functional aspects of the insular lobe in primates including humans. Brain Res Brain Res Rev 1996;22:229-44.

[6] Bantick SJ, Wise RG, Ploghaus A, Clare S, Smith SM, Tracey I. Imaging how attention modulates pain in humans using functional MRI. Brain 2002;125:310-9.

[7] Baron RM, Kenny DA. The moderator-mediator variable distinction in social psychological research: conceptual, strategic, and statistical considerations. J Pers Soc Psychol 1986;51:1173-82.

[8] Bornhovd K, Quante M, Glauche V, Bromm B, Weiller C, Buchel C. Painful stimuli evoke different stimulus-response functions in the amygdala, prefrontal, insula and somatosensory cortex: a single-trial fMRI study. Brain 2002;125:1326-36.

[9] Chakour MC, Gibson SJ, Bradbeer M, Helme RD. The effect of age on A deltaand C-fibre thermal pain perception. PAIN ${ }^{\circledR} 1996 ; 64: 143-52$.
[10] Chang YC, Lin WM, Hsieh ST. Effects of aging on human skin innervation. Neuroreport 2004;15:149-53.

[11] Chao CC, Hsieh ST, Chiu MJ, Tseng MT, Chang YC. Effects of aging on contact heat-evoked potentials: the physiological assessment of thermal perception. Muscle Nerve 2007;36:30-8.

[12] Chen JI, Ha B, Bushnell MC, Pike B, Duncan GH. Differentiating noxious- and innocuous-related activation of human somatosensory cortices using temporal analysis of fMRI. J Neurophysiol 2002;88:464-74.

[13] Cipolloni PB, Pandya DN. Cortical connections of the frontoparietal opercular areas in the rhesus monkey. J Comp Neurol 1999;403:431-58.

[14] Coghill RC, Sang CN, Maisog JM, Iadarola MJ. Pain intensity processing within the human brain: a bilateral, distributed mechanism. J Neurophysio 1999;82:1934-43.

[15] Cole LJ, Farrell MJ, Gibson SJ, Egan GF. Age-related differences in pain sensitivity and regional brain activity evoked by noxious pressure. Neurobiol Aging 2010;31:494-503.

[16] Collins DL, Neelin P, Peters TM, Evans AC. Automatic 3D intersubject registration of MR volumetric data in standardized Talairach space. J Comput Assist Tomogr 1994;18:192-205.

[17] Craig AD. How do you feel? Interoception: the sense of the physiological condition of the body. Nat Rev Neurosci 2002;3:655-66.

[18] D'Esposito M, Deouell LY, Gazzaley A. Alterations in the BOLD fMRI signal with ageing and disease: a challenge for neuroimaging. Nat Rev Neurosci 2003;4:863-72.

[19] Duerden EG, Albanese MC. Localization of pain-related brain activation: a meta-analysis of neuroimaging data. Human Brain Mapp 2013;34:109-49.

[20] Erpelding N, Moayedi M, Davis KD. Cortical thickness correlates of pain and temperature sensitivity. PAIN ${ }^{\circledR} 2012 ; 153: 1602-9$.

[21] Forman SD, Cohen JD, Fitzgerald M, Eddy WF, Mintun MA, Noll DC. Improved assessment of significant activation in functional magnetic resonance imaging (fMRI): use of a cluster-size threshold. Magn Reson Med 1995;33:636-47.

[22] Friston KJ, Frith CD, Turner R, Frackowiak RS. Characterizing evoked hemodynamics with fMRI. Neuroimage 1995;2:157-65.

[23] Friston KJ, Holmes AP, Worsley KJ, Poline JP, Frith CD, Frackowiak RS. Statistical parametric maps in functional imaging: a general linear approach. Human Brain Mapp 1995;2:189-210.

[24] Gagliese L, Melzack R. Age differences in nociception and pain behaviours in the rat. Neurosci Biobehav Rev 2000;24:843-54.

[25] Gagliese L, Melzack R. Pain in the elderly. In: McMahon SB, Koltzenburg M, editors. Wall and Melzack's textbook of pain. Philadelphia: Elsevier Churchill Livingstone; 2006. p. 1169-79.

[26] Geha PY, Baliki MN, Harden RN, Bauer WR, Parrish TB, Apkarian AV. The brain in chronic CRPS pain: abnormal gray-white matter interactions in emotional and autonomic regions. Neuron 2008;60:570-81.

[27] Gibson SJ, Farrell M. A review of age differences in the neurophysiology of nociception and the perceptual experience of pain. Clin J Pain 2004;20:227-39.

[28] Gibson SJ, Gorman MM, Helme RD. Assessment of pain in the elderly using event-related cerebral potentials. In: Charlton JE, Woolf $\mathrm{CJ}$, Bond MR, editors. Proc. VIth world congress on pain. Amsterdam: Elsevier; 1991. p. 527-33.

[29] Good CD, Johnsrude IS, Ashburner J, Henson RN, Friston KJ, Frackowiak RS. A voxel-based morphometric study of ageing in 465 normal adult human brains. Neuroimage 2001;14:21-36.

[30] Granot M, Granovsky Y, Sprecher E, Nir RR, Yarnitsky D. Contact heat-evoked temporal summation: tonic versus repetitive-phasic stimulation. PAIN ${ }^{\circledR}$ 2006;122:295-305.

[31] Grant JA, Courtemanche J, Duerden EG, Duncan GH, Rainville P. Cortical thickness and pain sensitivity in zen meditators. Emotion 2010;10:43-53.

[32] Harkins SW, Chapman CR. Detection and decision factors in pain perception in young and elderly men. PAIN ${ }^{\circledR} 1976 ; 2: 253-64$.

[33] Harkins SW, Davis MD, Bush FM, Kasberger J. Suppression of first pain and slow temporal summation of second pain in relation to age. J Gerontol A Biol Sci Med Sci 1996;51:M260-5.

[34] Harkins SW, Price DD, Martelli M. Effects of age on pain perception: thermonociception. J Gerontol 1986;41:58-63.

[35] Hayes AF. The simple mediation model. In: Hayes AF, editor. Introduction to mediation, moderation, and conditional process analysis: A regression-based approach. New York: Guilford Press; 2013. p. 85-122.

[36] Hofbauer RK, Rainville P, Duncan GH, Bushnell MC. Cortical representation of the sensory dimension of pain. J Neurophysiol 2001;86:402-11.

[37] Holmes AP, Friston KJ. Generalisability, random effects and population inference. Neuroimage 1998;7:S754.

[38] Huettel SA, Singerman JD, McCarthy G. The effects of aging upon the hemodynamic response measured by functional MRI. Neuroimage 2001;13:161-75.

[39] Hwang JH, Li CW, Wu CW, Chen JH, Liu TC. Aging effects on the activation of the auditory cortex during binaural speech listening in white noise: an fMRI study. Audiol Neurootol 2007;12:285-94.

[40] Iwata K, Fukuoka T, Kondo E, Tsuboi Y, Tashiro A, Noguchi K, Masuda Y, Morimoto T, Kanda K. Plastic changes in nociceptive transmission of the rat spinal cord with advancing age. J Neurophysiol 2002;87:1086-93.

[41] Katz J, Melzack R. Pain assessment in adult patients. In: McMahon SB, Koltzenburg M, editors. Wall and Melzack's textbook of pain. Philadelphia: Elsevier Churchill Livingstone; 2006. p. 291-304. 
[42] Keogh E, Hatton K, Ellery D. Avoidance versus focused attention and the perception of pain: differential effects for men and women. PAIN ${ }^{\circledR}$ 2000;85:225-30.

[43] Koyama T, McHaffie JG, Laurienti PJ, Coghill RC. The subjective experience of pain: where expectations become reality. Proc Natl Acad Sci U S A 2005;102:12950-5.

[44] Kuchinad A, Schweinhardt P, Seminowicz DA, Wood PB, Chizh BA, Bushnell MC. Accelerated brain gray matter loss in fibromyalgia patients: premature aging of the brain? J Neurosci 2007;27:4004-7.

[45] Kupers RC, Svensson P, Jensen TS. Central representation of muscle pain and mechanical hyperesthesia in the orofacial region: a positron emission tomography study. PAIN ${ }^{\circledR}$ 2004;108:284-93.

[46] Lieberman MD, Cunningham WA. Type I and type II error concerns in fMR research: re-balancing the scale. Soc Cogn Affect Neurosci 2009;4:423-8.

[47] Lin YH, Hsieh SC, Chao CC, Chang YC, Hsieh ST. Influence of aging on therma and vibratory thresholds of quantitative sensory testing. J Peripher Nerv Syst 2005;10:269-81.

[48] Logan BR, Rowe DB. An evaluation of thresholding techniques in fMRI analysis. Neuroimage 2004;22:95-108

[49] Lorenz J, Minoshima S, Casey KL. Keeping pain out of mind: the role of the dorsolateral prefrontal cortex in pain modulation. Brain 2003;126:1079-91.

[50] Luders E, Narr KL, Thompson PM, Woods RP, Rex DE, Jancke L, Steinmetz H, Toga AW. Mapping cortical gray matter in the young adult brain: effects of gender. Neuroimage 2005;26:493-501.

[51] Melzack R. The short-form McGill Pain Questionnaire. PAIN ${ }^{\circledR} 1987 ; 30: 191-7$.

[52] Merskey H. Classification of chronic pain. Descriptions of chronic pain syndromes and definitions of pain terms. Prepared by the international association for the study of pain, subcommittee on taxonomy. PAIN 1986;3(Suppl.):S1-226.

[53] Moayedi M, Weissman-Fogel I, Salomons TV, Crawley AP, Goldberg MB, Freeman BV, Tenenbaum HC, Davis KD. Abnormal gray matter aging in chronic pain patients. Brain Res 2012;1456:82-93.

[54] Moulton EA, Keaser ML, Gullapalli RP, Greenspan JD. Regional intensive and temporal patterns of functional MRI activation distinguishing noxious and innocuous contact heat. J Neurophysiol 2005;93:2183-93.

[55] Moulton EA, Pendse G, Becerra LR, Borsook D. BOLD responses in somatosensory cortices better reflect heat sensation than pain. J Neurosci 2012;32:6024-31.

[56] Nichols TE. Multiple testing corrections, nonparametric methods, and random field theory. Neuroimage 2012;62:811-5.

[57] Ochsner KN, Ludlow DH, Knierim K, Hanelin J, Ramachandran T, Glover GC, Mackey SC. Neural correlates of individual differences in pain-related fear and anxiety. PAIN $^{\circledR}$ 2006;120:69-77.

[58] Parkhouse N, Le Quesne PM. Quantitative objective assessment of periphera nociceptive C fibre function. J Neurol Neurosurg Psychiatry 1988;51:28-34.

[59] Petrovic P, Kalso E, Petersson KM, Ingvar M. Placebo and opioid analgesiaimaging a shared neuronal network. Science 2002;295:1737-40.

[60] Peyron R, Garcia-Larrea L, Gregoire MC, Costes N, Convers P, Lavenne F, Mauguiere F, Michel D, Laurent B. Haemodynamic brain responses to acute pain in humans: sensory and attentional networks. Brain 1999;122:1765-80.

[61] Peyron R, Laurent B, Garcia-Larrea L. Functional imaging of brain responses to pain. A review and meta-analysis (2000). Neurophysiol Clin 2000;30:263-88.

[62] Ploner M, Gross J, Timmermann L, Schnitzler A. Cortical representation of first and second pain sensation in humans. Proc Natl Acad Sci U S A 2002;99:12444-8

[63] Preacher KJ, Hayes AF. SPSS and SAS procedures for estimating indirect effects in simple mediation models. Behav Res Methods Instrum Comput 2004;36:717-31.

[64] Preacher KJ, Hayes AF. Asymptotic and resampling strategies for assessing and comparing indirect effects in multiple mediator models. Behav Res Methods 2008;40:879-91.

[65] Price DD. Psychological and neural mechanisms of the affective dimension of pain. Science 2000;288:1769-72.
[66] Quiton RL, Roys SR, Zhuo J, Keaser ML, Gullapalli RP, Greenspan JD. Age-related changes in nociceptive processing in the human brain. Ann N Y Acad Sci 2007; $1097: 175-8$.

[67] Rainville P, Bao QV, Chretien P. Pain-related emotions modulate experimental pain perception and autonomic responses. PAIN ${ }^{\circledR} 2005 ; 118: 306-18$.

[68] Rainville P, Duncan GH, Price DD, Carrier B, Bushnell MC. Pain affect encoded in human anterior cingulate but not somatosensory cortex. Science 1997;277:968-71.

[69] Raz N, Gunning FM, Head D, Dupuis JH, McQuain J, Briggs SD, Loken WJ, Thornton AE, Acker JD. Selective aging of the human cerebral cortex observed in vivo: differential vulnerability of the prefrontal gray matter. Cereb Cortex 1997; 7:268-82.

[70] Salthouse TA. Neuroanatomical substrates of age-related cognitive decline. Psychol Bull 2011;137:753-84

[71] Seminowicz DA, Davis KD. Cortical responses to pain in healthy individuals depends on pain catastrophizing. PAIN ${ }^{\circledR}$ 2006;120:297-306.

[72] Shackman AJ, Salomons TV, Slagter HA, Fox AS, Winter JJ, Davidson RJ. The integration of negative affect, pain and cognitive control in the cingulate cortex. Nat Rev Neurosci 2011;12:154-67.

[73] Sobel ME. Asymptotic intervals for indirect effects in structural equation models. In: Leinhart S, editor. Sociological methodology. San Francisco: JosseyBass; 1982 . p. 290-312.

[74] Sowell ER, Peterson BS, Thompson PM, Welcome SE, Henkenius AL, Toga AW. Mapping cortical change across the human life span. Nat Neurosci 2003;6:309-15.

[75] Tisserand DJ, Pruessner JC, Sanz Arigita EJ, van Boxtel MP, Evans AC, Jolles J, Uylings HB. Regional frontal cortical volumes decrease differentially in aging: an MRI study to compare volumetric approaches and voxel-based morphometry. Neuroimage 2002;17:657-69.

[76] Treede RD, Kenshalo DR, Gracely RH, Jones AK. The cortical representation of pain. PAIN ${ }^{\circledR} 1999 ; 79: 105-11$

[77] Truini A, Galeotti F, Romaniello A, Virtuoso M, Iannetti GD, Cruccu G. Laserevoked potentials: normative values. Clin Neurophysiol 2005;116:821-6.

[78] Tseng MT, Tseng WY, Chao CC, Lin HE, Hsieh ST. Distinct and shared cerebral activations in processing innocuous versus noxious contact heat revealed by functional magnetic resonance imaging. Human Brain Mapp 2010;31:743-57.

[79] Tzourio-Mazoyer N, Landeau B, Papathanassiou D, Crivello F, Etard O, Delcroix $\mathrm{N}$, Mazoyer B, Joliot M. Automated anatomical labeling of activations in SPM using a macroscopic anatomical parcellation of the MNI MRI single-subject brain. Neuroimage 2002;15:273-89.

[80] Valet M, Sprenger T, Boecker H, Willoch F, Rummeny E, Conrad B, Erhard P, Tolle TR. Distraction modulates connectivity of the cingulofrontal cortex and the midbrain during pain-an fMRI analysis. PAIN ${ }^{\circledR}$ 2004;109:399-408.

[81] Verdu E, Ceballos D, Vilches JJ, Navarro X. Influence of aging on peripheral nerve function and regeneration. J Peripher Nerv Syst 2000;5:191-208.

[82] Vogt BA. Pain and emotion interactions in subregions of the cingulate gyrus. Nat Rev Neurosci 2005;6:533-44.

[83] Vogt BA, Berger GR, Derbyshire SW. Structural and functional dichotomy of human midcingulate cortex. Eur J Neurosci 2003;18:3134-44.

[84] Wager TD, Davidson ML, Hughes BL, Lindquist MA, Ochsner KN. Prefrontalsubcortical pathways mediating successful emotion regulation. Neuron 2008;59:1037-50.

[85] Wang J, Eslinger PJ, Smith MB, Yang QX. Functional magnetic resonance imaging study of human olfaction and normal aging. J Gerontol A Biol Sci Med Sci 2005;60:510-4

[86] Wang Z, Yan C, Zhao C, Qi Z, Zhou W, Lu J, He Y, Li K. Spatial patterns of intrinsic brain activity in mild cognitive impairment and Alzheimer's disease: a resting-state functional MRI study. Human Brain Mapp 2011;32:1720-40.

[87] Worsley KJ, Marrett S, Neelin P, Vandal AC, Friston KJ, Evans AC A unified statistical approach for determining significant signals in images of cerebral activation. Human Brain Mapp 1996;4:58-73. 